\title{
Pascal M. Kitromilidis, La Révolution française et \\ l'Europe du Sud-Est, Athènes, éd. Poreia, 2000,194 p. ( $2^{\mathrm{e}}$ édition)
}

Amaury Faivre d'Arcier

\section{(2) OpenEdition \\ Journals}

Édition électronique

URL : https://journals.openedition.org/ahrf/4113

DOI : 10.4000/ahrf.4113

ISSN : 1952-403X

Éditeur :

Armand Colin, Société des études robespierristes

Édition imprimée

Date de publication : 1 décembre 2002

Pagination : 210-212

ISSN : 0003-4436

\section{Référence électronique}

Amaury Faivre d'Arcier, «Pascal M. Kitromilidis, La Révolution française et l'Europe du Sud-Est, Athènes, éd. Poreia, 2000,194 p. ( $2^{\mathrm{e}}$ édition) ", Annales historiques de la Révolution française [En ligne], 330 | octobre-décembre 2002, mis en ligne le 16 avril 2008, consulté le 24 avril 2022. URL : http:// journals.openedition.org/ahrf/4113; DOI : https://doi.org/10.4000/ahrf.4113

Ce document a été généré automatiquement le 24 avril 2022.

Tous droits réservés 


\title{
Pascal M. Kitromilidis, La Révolution française et l'Europe du Sud-Est, Athènes, éd. Poreia, 2000,194 p. ( $2^{\mathrm{e}}$ édition)
}

\author{
Amaury Faivre d'Arcier
}

1 Pascal M. Kitromilidis, professeur de sciences politiques à l'Université d'Athènes, directeur du Centre des recherches néo-helléniques à la Fondation nationale de la Recherche, est l'auteur de nombreux ouvrages sur la Grèce du XVIII ${ }^{\mathrm{e}}$ siècle (Rigas Vélestinlis. Théorie et action, 1998 ; Les Lumières néo-helléniques. Les idées politiques et sociales, 1996; La vision de la liberté dans la société grecque, 1992; ainsi qu'une édition grecque de l'œuvre de John Locke).

2 La première partie de ce nouvel ouvrage, la plus conséquente (plus d'une soixantaine de pages) pourrait presque se suffire à elle-même puisqu'elle évoque tous les thèmes qui seront abordés ultérieurement et permet d'exposer la problématique générale.

3 L'auteur commence par rendre hommage au grand historien roumain Nicolae Iorga qui, dans l'entre-deux-Guerres, fut l'un des premiers à vouloir rechercher les influences de la Révolution française dans le sud-est de l'Europe en dépassant le cadre territorial de l'Empire ottoman pour prendre davantage en compte le facteur humain (groupes sociaux, diasporas). P. Kitromilidis revient d'ailleurs sur la définition de cet espace géographique et culturel qui constitue, selon lui, le cadre historique de l'existence de l'hellénisme ou plus exactement de l'orthodoxie. Cet espace ne comprend pas seulement la péninsule balkanique au sud du Danube mais également les provinces méridionales de l'Empire des Habsbourg, les possessions vénitiennes de Dalmatie et d'Illyrie, Raguse ainsi que les ports de Venise et Trieste où sont concentrées d'importantes communautés balkaniques, enfin la côte occidentale de l'Asie Mineure et Chypre. Chronologiquement, l'étude ne saurait, d'après lui, être circonscrite à la décade 1789-1799 car l'éveil des mouvements nationaux se développe surtout pendant la période napoléonienne. 
Reprenant un terme cher au professeur Michel Vovelle, il s'efforce ensuite de comprendre comment, dans cette entité géographique originale, s'est "forgée la mentalité révolutionnaire» (titre donné au chapitre), en y mesurant les échos des idées nouvelles.

5 Il distingue ainsi plusieurs niveaux d'influence et de réceptivité de l'idéologie révolutionnaire. Il y a en premier lieu les régions qui sont au contact direct avec l'administration française et qui subissent de plein fouet ses implications en terme de destruction de la féodalité et des privilèges, de réformes politiques et sociales. Telles sont les Iles Ioniennes, occupées à deux reprises (de 1797 à 1799, et de 1807 à 1814), et les provinces Illyriennes de Dalmatie, Istrie et Croatie (de 1806 à 1814). Il y a ensuite les représentants officiels et les agents secrets de la France révolutionnaire et napoléonienne qui, avec leurs réseaux de liaisons, véhiculent dans les grands centres urbains et les ports de l'Empire ottoman (à commencer par Constantinople) les attentes et les espoirs mais aussi les craintes d'un changement. Viennent enfin les intellectuels grecs de la diaspora, témoins oculaires des événements dans la capitale parisienne (Koraïs, Stamaty, Philippidis...), dont les écrits et les initiatives politiques présentent un intérêt particulier pour l'histoire comparée des idées.

6 À n'en pas douter, les masses paysannes de la société balkanique ne sont pas influencées par ce mouvement qui ne trouve résonance qu'auprès de certains milieux cultivés de l'aristocratie foncière (les Bogiares) et dans les classes urbaines des négociants. Les bases sociales de la réceptivité aux idées révolutionnaires sont donc assez faibles sans pour autant pouvoir être niées.

7 La seconde partie porte le titre : «La critique libérale de la Révolution française ». L'auteur propose une lecture du témoignage du savant Adamantios Koraïs (1748-1833) qui, dans sa Correspondance, «formule les inquiétudes psychologiques, spirituelles et politiques ainsi que les problématiques qui annoncent la critique libérale de la Révolution ».

8 Installé à Paris au mois de mai 1788 pour y compléter ses recherches en vue d'une édition des textes Hypocratiques, Koraïs est, avec Constantin Stamaty, l'un des rares Grecs à être le témoin oculaire des événements révolutionnaires. Certains faits, dont P. Kitromilidis cite quelques passages intéressants, semblent l'avoir profondément marqué : ainsi par exemple, le transfert de la dépouille de Voltaire au Panthéon (juillet 1791), la substitution de l'acclamation traditionnelle "vive le roi» par la clameur révolutionnaire "vive la Nation », ou encore la mort de Louis XVI. Ses attentes sont à leur comble en 1796 lorsque les Français entreprennent la conquête de l'Italie et des îles Ioniennes; mais l'auteur explique aussi que toutes les parties de la communauté orthodoxe et en particulier les classes dirigeantes locales, qui craignent l'extension de la Révolution, ne partagent pas l'enthousiasme de Koraïs.

9 P. Kitromilidis le situe politiquement dans le courant de pensée représenté en France par Condorcet et les Girondins dans les premières années de la Révolution, par les Idéologues et $\mathrm{M}^{\text {me }}$ de Staël sous le Directoire. Sa correspondance ultérieure avec Jérémy Bentham et Thomas Jefferson d'une part, et ses deux initiatives de traduction pour promouvoir les idées nouvelles dans la Grèce insurgée d'autre part (la Proclamation des Droits de l'homme et du citoyen et l'Essai sur les garanties individuelles de Pierre Claude François Daunou, l'un des plus fameux Idéologues) l'associent directement à la production littéraire libérale de la Révolution française. 
10 Dans la troisième et dernière partie de son livre, P. Kitromilidis analyse ce qu'il appelle «le radicalisme balkanique » comme courant d'idées et comme action politique, qui préfigure et explique les événements révolutionnaires des années 1820 . Ce mouvement prend forme dans la dernière décennie $d u X V_{I I I}{ }^{e}$ siècle et tire ses références idéologiques chez plusieurs auteurs des Lumières (Rousseau, Mably, Montesquieu) dont les oeuvres sont traduites en grec dès le début de la Révolution.

11 Ce radicalisme est visible à trois niveaux. Dans le programme politique de Rigas Velestinli (1757-1798) ${ }^{1}$ qui s'inspire de la Constitution française de 1793 et tranche avec les conceptions libérales de Koraïs; dans l'effervescence qui règne dans les milieux cultivés de la Grèce occidentale à la suite de l'occupation des Sept îles par les troupes françaises; enfin, dans les centres de la diaspora hellène en Europe centrale et orientale et dans certains ports de la Méditerranée (Livourne, Marseille), lesquels deviennent des points de contact du monde balkanique avec les idées nouvelles bien sûr (par le biais de la littérature et de la presse) mais aussi avec les pratiques politiques révolutionnaires. Vienne joue à cet égard un rôle majeur dans la diffusion à Bucarest, à Jassy, à Zagreb et à Raguse des brochures et libelles édités en grec et en serbo-croate ainsi que dans les tentatives de déstabilisation des principautés danubiennes et de Serbie sous domination ottomane.

12 Les deux manifestations les plus éclatantes de ce radicalisme précurseur et annonciateur des mouvements nationaux du début du XIX siècle sont la conspiration de Martinovi à Vienne et à Budapest dans les années 1795-1796, à laquelle participent les Jacobins de Croatie et de Serbie, et la tentative de Rigas peu de temps après en 1798, initiatives qui se soldent l'une et l'autre par un échec. L'auteur montre très bien comment la répression qui s'ensuit contraint le mouvement révolutionnaire balkanique, qui n'est pas homogène, à déplacer son cadre d'action hors des frontières de l'Empire austro-hongrois et à s'organiser en sociétés secrètes dont nous ne connaissons que les noms. Les circonstances politiques dans les pays balkaniques font que ce radicalisme comme action politique, comme langage symbolique et comme vision de programme intervient à un moment où, en France, il est déjà vaincu après la chute des Jacobins et l'échec de la « République de la Vertu » qu'ils voulaient créer.

13 L'un des intérêts majeurs de cet ouvrage est d'aborder chacune de ces questions en la replaçant dans une approche historiographique et de bien décrire le discours politique des précurseurs révolutionnaires grecs à partir du faible corpus de textes dont nous disposons. S'agissant d'une deuxième édition (la première a été publiée en 1990), P. Kitromilidis a pu aussi l'enrichir des nouveaux apports de la recherche.

\section{NOTES}

1. Rigas est né dans la petite bourgade de Vélestino, non loin du port de Volos (Thessalie). Après la guerre d'indépendance de 1821, on ajouta à son nom le mot « Féraios ", ancien toponyme de Vélestino. 